\title{
THE CONTRADICTORY NATURE OF TEACHER EDUCATION IN THE PARTNERSHIP BETWEEN UNIVERSITY AND SCHOOL
}

\author{
André Machado Rodrigues, Cristiano Rodrigues de Mattos \\ University of São Paulo, Brazil \\ E-mail: rodrigues@if.usp.br, mattos@if.usp.br
}

\begin{abstract}
There is a growing understanding that teacher education should not be handled either exclusively by the University or in School settings. Nevertheless, the issues on how to foster a fruitful partnership between these two different institutions remains an open and challenging point. The practicum is a critical point in the pre-service teacher's development, usually because it is the first time they have to face the concrete professional issues, which they only had a partial view of as students. This research is a year-long inquiry on practicum in the Physics teaching program developed in the Institute of Physics at the University of São Paulo, Brazil. Drawing on cultural-historical activity theory, contradiction is used as an explanatory principle to examine change and development in the practitioners' activity. Therefore, the research includes in the analytical framework the contradictions and the processes of overcoming it. Examples are provided in which there is little control therefore demanding extra efforts but makes room for active participation. The data analysis indicates that the source of agency and activities transformation is precisely a contradictory process, which might be overlooked. The pre-service teachers' agency is shaped by contradictory process within the activity - practicum - rather than aligned forces pushing it toward autonomy, student sensitiveness or professional identity.
\end{abstract}

Keywords: initial teacher education, practicum, university-school partnership, qualitative research.

\section{Introduction}

There is a growing understanding that teacher education is a complex system of activities that should not be handled either exclusively by the University or in School settings. Nonetheless, how to better develop the partnership between these two different institutions remains a significant challenge (Akkerman \& Bruining, 2016; Harfitt \& Tavares, 2004; K. Zeichner, 2009). The University and basic School shared commitment - with focus on the teaching-learning process of future teachers - is the cornerstone of the initial teacher's education program. Ideally, pre-service teachers would have opportunity to circulate in and experience both environments. Although literature indicates a variety of models, mechanisms and strategies to better integrate School and University in this joint enterprise, the core ideas float around the harmful effect of keeping these two institutions apart and the urgent need for more organic integration between these instances of pre-service teachers' development.

Nevertheless, the process of integrating different institutions and stakeholders is rarely unproblematic. Indeed, the boundary-crossing is a challenging process where practitioners are permanently invited to face the contradictions nested in it (Engeström, Engeström, \& Kärkkäinen, 1995; Tsui \& Law, 2007). In addition, it is pivotal to bear in mind that, in itself, teaching is a complex activity with multiple demands in many levels (Shulman, 1987; Yamagata-Lynch \& Haudenschild, 2009). Today teachers must be aware of cultural differences, inclusion and exclusion issues, curriculum development, local and large scales assessment, students' engagement and progression learning etc. 
André Machado RODRIGUES, Cristiano Rodrigues de MATTOS. The contradictory nature of teacher education in the partnership between university and school

\section{PROBLEMS \\ OF EDUCATION \\ IN THE $21^{\text {st }}$ CENTURY \\ Vol. 76, No. 1, 2018}

The practicum $^{l}$ is a critical point in the pre-service teachers' development, usually because it is the first time they have to face the concrete professional issues, which, as students, they only had a partial view of. The transition between University and School throughout the practicum goes far beyond the institutional shift (Anagnostopoulos, Smith, \& Basmadjian, 2007). Pre-service teachers experience a change in moving from the position of students towards a position of teacher. Moreover, in those transitions it is expected that pre-service teachers take part in teaching activity. Meanwhile, they have to master and actively apply it in such complex processes.

Frequently, practitioners tend to see practicum - embodying the hierarchical relationship between University and School - as a unilateral movement that goes from the University to School. Curiously, such perspective could be found in both institutions. On the other hand, those perspectives that see the School as an extension of the University or a merge of both institutions in one general event are unable to see the contractions in, within and between them (Jooganah \& Williams, 2016). Even though School and University have similarities, they are indeed radically different institutions, which have their own ways of organizing their educational tenets as well as diverse cultural and historical backgrounds.

Assuming that practicum is a highly complex activity which stems from the encounter of School and University, Fazio, Melville, \& Bartley (2010, p. 678) express theoretically and methodologically the challenges implied in practicum. The authors conclude that "[...] the complex reality of knowledge, motivation, beliefs, capability, and context are clearly intertwined by a complex web of dialectical interactions, which in turn concomitantly determine teachers' actions." Therefore, the practicum activity is not a merely knowledge transfer from University to School. Accordingly, in their research on University-School collaboration, Anagnostopoulos et al. (2007, pp. 150-151) concluded that:

Teacher educators are increasingly being called on to improve the learning opportunities they provide beginning teachers. This necessitates reenvisioning teacher education's multiorganizational terrain as a source of not only beginning teacher learning but also of our own learning as teacher educators and the learning of our K-12 colleagues.

This multidirectional expertise is a key concept, which provides a better picture on University-School connections.

\section{The Research Questions}

This research is a yearlong inquiry on practicum in the Physics teaching program of the University of São Paulo, Brazil. The practicum carried out by pre-service teachers in middle and high Schools in the urban area around the University campus will be examined. Therefore, the research aims to scrutinize this particular partnership between University and School and answer:

1) What kind of contradictions emerged?

2) How the contradictory processes in the practicum shape the pre-service teachers' agency as future teachers?

The initial hypothesis is that the contradictions within the partnership are not a consequence of a careless planning or a direct impact from the lack of infrastructure. Rather, the con-

1 In Brazilian teacher education programs, the practicum is considered the group of mandatory activities that pre-service teachers carry out in School. A variety of activities and small tasks might be designed for pre-service teachers which run from classroom observation to teaching practices. This term may change across different countries or teacher education programs - internship, school-based activities, school placement etc. 
tradictions that shall be presented and discussed are an inherent part of this encounter between two institutions with different initial goals.

\section{A Glance into the Brazilian Teacher Training Program}

Since 1996 with the last Brazilian National Education Guidelines and Standards Law, the path to become a teacher is, to some extent, unified. In order to teach Physics in middle and high School classes the student must attend a specific undergraduate program available in universities and high education institutions. Moreover, teacher certification programs are not part of the national education policy and they barely exist as state or municipality education policy. Particularly, to be a middle and high School teacher, the students should choose the teaching career form they apply for admission at University. Indeed, in the federal University system there are just a few universities that offer the course structure as two years of specific content disciplines, and only later, the students are asked to choose the teaching course path.

The Brazilian National Guidelines for Teacher Education determine that from 3,200 hours of course, 400 hours students are supposed to dedicate for practicum and School placement (Ministry of Education of Brazil, 2015, p. 11). Furthermore, the practicum involves very different sets of tasks in the School such as observations, study of School documents, proposing workshops, participation in a variety of School meetings, and the teaching of specific subject matters (idem).

Recent trends indicate a progressive increment of the time spent in School-base activities (Janssen, Westbroek, \& Doyle, 2014; Lampert, 2010), although the concrete institutional instruments that enable pre-service teachers' development are not very clear. In other words, the education policy has provided the conditions to increase quantitatively the time pre-service teachers spend in School. However, it is not explicit how to enhance quality (Gatti, 2014).

At University, the students choose the career from the beginning. However, not all preservice teachers aim the teaching profession. In many cases, the pre-service teachers are not sure whether they want to be a teacher or not (Hong, 2010). The profession drops out and the low adherence to teaching career is one of the major issues for initial teacher education in Brazil.

For the last ten years, particularly in the Brazilian context, the educational system was driven by a combination of high levels of social inequality and a sharp capitalist development. Specifically, teacher education is suffering with a well-known contradiction: the need for a vast squad of new "domesticated teachers" in order to keep in track the economic development (Sobrinho, 2006). A direct effect is the massification process where teacher education is getting quicker and homogenized in a high scale (Barretto, 2015). Villani et al. (2009) outlined how such contradictions have been built in the historical development of Brazilian teacher education programs. Although the University specialists point towards a complex and autonomous education, they do not desist from control and domain over teachers work (idem).

\section{Cultural-Historical Activity Theory}

The practicum is a highly complex activity where School and the University meet, combining aspects of University demands, scripts and routines with those from School daily life. To handle such a complex and dynamic object the research is drawing on Cultural-Historical Activity Theory (CHAT) seeking to provide a robust framework rooted in dialectical materialism and stemmed from Vygotsky's research tradition (Vygotsky, 1978).

According to Engeström (2001, pp. 134-135) the "concept of activity took the paradigm a huge step forward in that it turned the focus on complex interrelations between the individual subject and his or her community." In this perspective, the human activity is a mediated process 
André Machado RODRIGUES, Cristiano Rodrigues de MATTOS. The contradictory nature of teacher education in the partnership between university and school

\section{PROBLEMS \\ OF EDUCATION \\ IN THE $21^{\text {st }}$ CENTURY Vol. 76, No. 1, 2018}

in which human beings change the surrounding world, whereas they are transformed by it. A two-way process that changes the concrete material relation simultaneously changing the consciousness. The concept of activity as presented by Engeström $(1987,2001)$ is a well-known way of conceptualizing organizations, cross-boundary processes and institutional interactions insofar it enables the researcher to relate dialectally individual and collective features of transforming activities.

Engeström (2001) proposed five principles in which activities are constituted:

1) activity is the unity of analysis;

2) the activity system is multivoicedness as an entanglement of different perspectives from the subjects of the activity;

3) the activity is historical, i.e., activity system is shaped and develops through time;

4) contradictions and the process of overcoming them are the source of change, innovation and development in an activity system;

5)the activity expands, changing qualitatively.

All those five tenets of CHAT approach work as heuristics principles compounding its basis and consequently they should be seen integrally related to one another. Considering this unity, the research is focusing on the role of contradiction in the development of a cross-boundary practice - the practicum.

\section{The Role of Contradictions}

The common use of the term contradiction refers to dual opposite positions that contradict each other. The formal logic influence in the common thinking associates contradiction with a sort of blind alley of the thought in a problem-solving process. In this vein, contradiction must ultimately be avoided in any process of conceptualization since it means a logical error (Ilyenkov, 1977). The fundamental law of non-contradiction in classical formal logic expresses that a statement and its denial cannot both be true at the same time. However, in any other dialectical approach, contradiction has a radically different meaning:

Contradiction is not the end of the matter, but transitional point of stability, an aporetic movement of reflection that must cancel itself out at a higher ground than can be afforded by any of the concepts at the present level (Hahn, 2007, p. 38).

According to Engeström (2001, p. 137), in cultural-historical activity theory the term contraction is the "historically accumulating structural tensions within and between activity systems", indicating that "dialectics deals with systems in movement through time." (Engeström \& Sannino, 2011, p. 370). This means that contradictions are embodied in the activity. From this perspective, the common unfruitful misunderstandings and misuses of the contradiction as an explanatory principle are in the inquiries that ignore movement and concreteness, i.e. historical development and its complexity.

Ultimately, the contradiction is not an analytical mistake, but an explanatory principle to examine change and development in the practitioners' activity. Therefore, one should include in the analytical framework the contradictions and the processes of overcoming it.

\section{Methodology of Research}

\section{General Background}

In 2009, within the Physics teacher training program, a relatively stable format for a discipline entitled Practice of Physics Teaching was consolidated. This discipline aims at articulating the Physics specific content matter, pedagogical theory, and the practice done at 
School placements. Its syllabus starts with the objective of the course: "to enable the students [pre-service teachers] to develop, autonomously, the integration of the contents of Physics and pedagogical ones, initiating them [pre-service teachers] into professional practice" (Institute of Physics, 2008, p. 10). From the outset of the program, the pre-service teachers must engage in School placements (practicum) at specific partner public Schools. It also involves much more guided assignments to be done at School than the pre-service teacher uses to perform in previous moments in the program. In 2010, several working routines were more stabilized and synchronized with partner Schools. For example, the number of visits, didactic material distribution, specific procedures to develop the experiments in the classroom and the partnership among pre-service teachers started to gain a stable format. The coordination of actions was, at the same time, process and product of the University and School mutual acknowledgment. Hence, School mentors and the University professors intensified the planning meetings to look for joint solutions of issues such as lack of materials, better synchronism between School and University tasks, align pedagogical approach within the classroom.

During the implementation of the teacher educations reforms, University staff started knowing some aspects of School routines by a kind of trial and error process. However, even with a stable routine at University, the inverse way remains practically impossible, considering that Schools are not seen by the practitioners as an empowered institution for teachers' instruction, and thus having little influence into University educational system decisions (Fazio et al., 2010; Whitney, Golez, Nagel, Nieto, \& Nieto, 2002).

One of the hardest problems during 2010 was the School teacher - mentor - absences throughout the year. Since there is no institutional formal compromise among University and mentors, many of them were not authentically involved with the pre-service teachers' assignments at School, the implications of this aspect shall be discussed later in this paper. In many cases, the presence of pre-service teachers at the classroom was seen as an opportunity for the mentor to accomplish other small works, thus pre-service teachers conducted the classes without proper teacher supervision neither orientation. A similar situation is highlighted by Edwards and Protheroe (2004, p. 194) saying that mentors "with students in their classrooms were considered to have increased freedom to undertake other work in School, hence they were regularly absent from the classroom." That situation was not general, touching only part of the pre-service teachers under specific mentor's supervision.

The general activity was compounded by two-week cycles in two different layers each - planning and teaching. During the first week of the planning layer, the University professor presents a draft of the lesson plan and in the next week the pre-service teachers along with mentors design hands-on assignments. During the first week of the teaching layer, pre-service teachers develop Physics experiments and hands-on activities at School and in the next week, they spend some time evaluating the previous Practicum lessons in class discussions at University. The cycles feed each other with new information.

\section{Sample Selection}

Roughly 20 hours of video recording and 241 weekly written reports produced by 52 pre-service teachers working in pairs at School in 2010 was considered to select a representative sample. Furthermore, some field notes were used for a substantive triangulation of the data (Kadri \& Roth, 2015; Roth, 2005). All the participants signed the research agreement explicitly discussed at the beginning of the data gathering. Additionally, the participants' names in the paper are pseudonyms. 
André Machado RODRIGUES, Cristiano Rodrigues de MATTOS. The contradictory nature of teacher education in the partnership between university and school

F EDUCATION

IN THE $21^{\text {st }}$ CENTURY

Vol. 76, No. 1, 2018

92

\section{Instrument and Procedures}

Data were gathered at the Physics teacher education course at University of São Paulo (Brazil) in a two year-long research project. Although some pieces of information and impressions from high School students and mentors were collected, data gathering was focused primarily on pre-service teacher experiences and action within the whole system. A camera was fixed at the classroom corner and the dialogs transcription - originally made in Portuguese - was translated into English. Each excerpt was marked with a number that refers to original marks made in the speech turns' transcription.

Table 1. Timetable and description of the topics discussed over 2010 within video recording data.

\begin{tabular}{|c|c|c|c|}
\hline $\mathrm{N}$ & Date & Time length & Topics discussed and general features. \\
\hline 1 & February, 22th & $86 \min$ & $\begin{array}{l}\text { Professor explanation on courses, practicum routines and rules. Debate about } \\
\text { the text "How people learn" (Bransford, Brown, \& Cocking, 2000). }\end{array}$ \\
\hline 2 & March, 1st & $37 \mathrm{~min}$ & $\begin{array}{l}\text { Pre-service teachers' seminar about "energy conservation and transformation". } \\
\text { Debate over concept map of energy. }\end{array}$ \\
\hline 3 & March, 8th & $97 \mathrm{~min}$ & $\begin{array}{l}\text { Hands-on experiment with pre-service teachers on energy transformation and } \\
\text { process of respiration. }\end{array}$ \\
\hline 4 & March, 15th & $95 \min$ & $\begin{array}{l}\text { Work in groups on an experiment of thermodynamics. Pre-service teachers' } \\
\text { seminar on heat and energy as a product of the discussion groups. }\end{array}$ \\
\hline 5 & March, 22th & $98 \mathrm{~min}$ & $\begin{array}{l}\text { Work in groups on an experiment in electromagnetism. Organization of the } \\
\text { pairs' work in schools, set on schedule and timetables. }\end{array}$ \\
\hline 6 & April, 5th & $107 \min$ & $\begin{array}{l}\text { Final preparation for school placement. Talk about the experiences and hands- } \\
\text { on activities. Some conversation in groups. }\end{array}$ \\
\hline 7 & April, 19th & $63 \mathrm{~min}$ & $\begin{array}{l}\text { General discussion on first experience in school. Some problems and many } \\
\text { pre-service teachers' frustrations. }\end{array}$ \\
\hline 8 & May, 3rd & $95 \mathrm{~min}$ & $\begin{array}{l}\text { Continuation of the discussion on school placement experiences. More specific } \\
\text { actions in school and discussions on the general characteristics of the schools. }\end{array}$ \\
\hline 9 & May, 17 th & $106 \min$ & $\begin{array}{l}\text { Discussion on school assignments and hands-on activities. Debate on agency } \\
\text { and commitment with the school interventions. }\end{array}$ \\
\hline 10 & May, 31st & $109 \min$ & $\begin{array}{l}\text { Experienced teacher gives a talk about violence and teacher's action at school } \\
\text { to control and deal with difficult situations. }\end{array}$ \\
\hline 11 & June, 7 th & $92 \mathrm{~min}$ & General discussion on major difficulties at school placement. \\
\hline 12 & August, 2nd & $100 \mathrm{~min}$ & Elaboration and organization of laboratory guides. Group discussions. \\
\hline 13 & August, 30th & $88 \mathrm{~min}$ & $\begin{array}{l}\text { Pre-service teachers present some feedbacks about the work at school place- } \\
\text { ment. }\end{array}$ \\
\hline 14 & $\begin{array}{l}\text { December, } \\
\text { 13th }\end{array}$ & $52 \mathrm{~min}$ & $\begin{array}{l}\text { Evaluation meeting and general discussion on year performance. Pre-service } \\
\text { teachers point out prominent problems and make some suggestions. }\end{array}$ \\
\hline
\end{tabular}

\section{Data Analysis}

The thematic content analysis was done (Kapustka, Howell, Clayton, \& Thomas, 2009) and data was coded using a hybrid system of theory-driven and data-driven categories (Fereday $\&$ Muir-Cochrane, 2008). The discussions at classroom were described and characterized using a set of data-driven categories (Edwards \& Protheroe, 2004). Especially for the case study presented in this paper an overlapping of critical situations, agency and activity change was observed. 


\section{Connecting University and School}

Considering the concrete conditions to establish the practicum activity, one of the very first challenges was to wave partnerships with the Schools around the University campus. The University professor in charge of practicum was responsible to begin the negotiation with School principals. At the very first contacts with some schools' principals, the University professor had unsuccessful attempts to carry out a joint project. This initial resistance is partly due to the criticism that School staffs use to receive University people when they adhere to this sort of partnership. Principal and teachers use to interpret that University activities include School only as a scenario for researches and, in return, University gives faultfinding critics. It was identified, during the initial visits to the Schools, that this sort of understanding repels Schools and teachers from initial teacher education and influences Schools that had no previous interaction with the University. During the interview, the University professor also confirmed such resistance.

A fruitful response came only through finding and contacting directly teachers that are willing to mentor pre-service teachers with no reward but the experience of mentoring. Ultimately, the informal and non-institutionalized contact indicates the burdensome aspect of developing the partnership at School level. The School and University partnership was not established at an institutional level, rather it was a personal commitment between mentors, University professor and pre-service teachers.

On the one hand, it entails that School teachers that become responsible for the development of the partnership should be fully committed and personally involved in the mentoring activity. This personal engagement is one of the key elements to sustain such a non-institutionalized partnership. This commitment also gives much more freedom of action to subjects of the activity. The ill-structured and less bureaucratized relationship left space for local individual initiatives and collaborative action, on the other hand, a non-institutionalized relationship requires from the subjects extra efforts to carry out even small coordinated actions. Moreover, it makes the partnership far more fragile as it relies primarily on personal commitment. Occasionally teachers willing to take part in mentoring have overload of work, which might compromise the engagement in a long run.

Nevertheless, this problematic situation of teacher's work overload might help to make some room for agency emergence. The pre-service teachers ended up receiving less attention than what was initially planned, and the mentoring process turns out to be much looser. This general scenario somewhat shaped participants' agency within this activity system. The protocols to solve any small problem were very flexible and have to be done case by case.

One unexpected consequence, unfolded by the fragmentation of the University action in School, was the simultaneous activities developed by different groups and subject matters. Only after ten months the Physics group finds out that there was a different group from Chemistry developing Practicum in the same Schools. Those actions reach the Schools from distinct sides, showing the disjunction within the University. From the researchers' perspective, it is a consequence of having a particular connection - one by one - and not a connection between two whole institutional activities.

\section{Embedded Activities}

Even though it is explicitly called 'School-based activity' in opposition to 'campusbased activities', one should ask to what extent the practicum is integrated with School activity. Even a small School activity is assembled by many different actions and operations. Although 
André Machado RODRIGUES, Cristiano Rodrigues de MATTOS. The contradictory nature of teacher education in the partnership between university and school

IN THE $21^{\text {st }}$ CENTURY Vol. 76, No. 1, 2018

94

classroom lessons are central to understand the schooling process, there are many other aspects to consider such as teachers meetings, planning, assessing, teacher-parent relationship etc. The social interaction processes grown outside the classroom indicate how pre-service teachers have to behave within the classroom. During the weekly meeting with the University professor, the pre-service teachers reported many impacting events from outside the classroom, for instance, the problem of where they could find extra materials for experimental activities, what to do with disruptive students or what type of extra support they might get from other School teachers.

Although the partnership between University and School has some instance of collaboration, the situation could be considered as a University activity nested within School context. The major empirical indicator is associated with pre-service teachers' reports on successful lessons. They commonly describe successful lessons as those in which they were able to develop the full planned lesson, fulfilling all the planned steps for the experimental activity. Mainly in the beginning of the academic year, they were attracted by the idea of the fulfillment of the experimental protocol as the objective benchmark for successful lessons and seldom mentioning students learning or well-being as something to take into account. This sort of educational goals narrowing happens mainly because pre-service teachers are indeed engaged in a University activity, even though all the events happen in the School context. They are answering to University expectations and standards.

In other words, pre-service teachers start the practicum committed with the University within School though. Ultimately, this commitment with the University goals (final grade, their own learning and development, accomplishing experimental protocols, etc.) not only shapes the pre-service teachers' agency in the practicum, but also determines how well they connected themselves to School life.

The class was interested, but the students were very dispersive. We could not apply the entire experiment until the end. The second class was hectic, displayed less interest and one group did nothing ... In this class, we also could not apply the experiment until the end. (Pre-service teachers' weekly report: Mellisa and Rebecca, April 2010)

This excerpt reflects the over-concern with the experiment, rather than with students' needs. They frequently replace the students' learning by students' interest. It happens because the student's engagement in the lesson is the first level of evaluation pre-service teachers have available. There is a significant shift in the reports, showing that pre-service teachers' activity moves towards students learning, which may work as an empirical indicator for pre-service teachers' connectedness to School activity.

Furthermore, the process of unidirectional connection between University and School is not completely clear to pre-service teachers, making shifts in their thinking and behavior much slower. It indicates that practicum was not a fully shared activity, since it kept on intense subordination ties with the University. This aspect shows up in a variety of ways, when the lesson planned in the University contradicts with the current practice in School.

I took the advantage that the teacher was not there and had the freedom of asking for the students' notebooks. I took a quick look. 'Guys, let me check your notebooks.' I looked one by one and I was like ... [shocked]. Because, until now, they have only half page of Physics. (Pre-service teacher group discussion: Fernando, May 2010)

Indeed, pre-service teachers have difficulties to envision what happens in School when they are not present. As they have a limited connection with the School, it is not an easy task to figure out the class and School lives. 


\section{Disruptive Dynamics or Mismatching Routines}

The encounter of two different institutional dynamics and historical backgrounds affects pre- service teachers' work in School. It is important to take into account that the University calendar, routines, hierarchical organization, protocols and ways of doing things - the whole cultural milieu - as well as the University goals within the practicum shape pre-service teachers' activity. In the first five weeks that pre-service teachers spent at school, conducting the planned lessons - all including weekly hands-on experiments - they dedicated some effort trying to match the different demands in both institutions. The weekly reports were largely focused on School institutional ambiance.

In many cases, during the discussion in the University they developed complex comparisons to contrast University and School routines. In spite of the particularities of each school, part of the School routines are familiar to them, and, somehow, they are familiar with the students' activity in the School, however the teachers' activity is completely new for them.

The examined teacher education program uses to accept candidates from different parts of Brazil, especially from the countryside where Schools have a very different social structure. Some pre-service teachers get surprised with the large difference from when they used to go to School.

The main point here is that initial teacher education is not a clear goal for School. The whole School organization, all the components of School activity are settled around and oriented toward student learning as the core outcome. In many cases, practicum is seen as a marginal task, which may disturb the School regular routines. This is not a particular perspective from a teacher or a principal rather than an underpinning objective of School organization. For a novice it is not a simple task to understand the School organization and how it reaches its goals as reported in the weekly discussion.

For instance, in the lesson named 'vector race', students should learn about vectors. The 'vector race' is a game that should be carried out in order to introduce the concepts of addition and multiplication of vectors. One of the pre-service teachers - Fernando - decided to break the planning previously made in the University and changed the course of actions during the class. He justifies it, saying:

What happened this specific day is that they [students] simply did not know anything about vectors. They knew it was an arrow. [...] In an entire class, no one could understand how the rules of the game worked. There was no way to play. So... you're saying we have to follow the script, then we do not. We did not follow the script ourselves. I could not follow the lab protocols. But you do not have to worry about the student. When we decided to change the script, it means we were concerned about the student. But isn't the purpose just to use the lab protocols to teach something? (Pre-service teacher group discussion: Fernando, May 2010)

This example expresses the contradiction of two divergent dynamics, as well as of their goals. In this case, to break with the University planning and commitment, means to respect the students timing and needs. This disruptive agency, which changed the course of actions as well as the set of commitments, is a critical moment in practicum. In other words, the contradiction moves the edge between University and School organizational dynamics.

\section{Identity Formation as a Contradictory Process}

One of the main contradictions affecting directly pre-service teachers' engagement and disposition to try out, is the fact that, although they are in a teacher' training program, they do not necessarily mean to be teachers at the end of the process. In an initial questionnaire, only $56.3 \%$ (out of 82 answers) of pre-service teachers have clear intention to become a high School 
André Machado RODRIGUES, Cristiano Rodrigues de MATTOS. The contradictory nature of teacher education in the partnership between university and school

\section{PROBLEMS \\ OF EDUCATION \\ IN THE $21^{\text {st }}$ CENTURY Vol. 76, No. 1, 2018 \\ 96}

teacher afterwards. This point was especially critical in the moment of practicum, since the pre-service teachers had to actively face their professional future. In another moment, where the course content is focused and exclusively held in the University, the pre-service teacher could postpone the professional issues. However, the practicum touches these issues in a very concrete way.

Although the University staff knew the critical point of pre-service teachers' interest in entering in teaching career, this topic was overlooked during the class discussions at the University. The teachers' identity - as well as their belonging - may work as an intermediate concept indicating how the subjects are engaged in the teaching activity.

I have learned that teaching practice does not depend solely on techniques and strategy, but also has a very important human element. Even if I use the best educational techniques and strategies, if I cannot instigate, encourage and show that what I teach has some relevance in the student's life, my practice will be quite difficult, and the results will probably not be long lasting. [...] So, if encouraging students is an essential part of teaching practice, how to do it in an environment where you are discouraged from the very first moment? (Preservice teachers' weekly report: Eric, December 2009)

This excerpt presents that the pre-service teachers were in a critical moment for his identity formation. Nevertheless, the experiences in School facing at concrete situations are not always pleasant or encouraging. Throughout research pre-service teachers reported frustration, stress and work overload.

The practicum will work as a first meeting with teaching practice. I expect that there are discussions about the career and its responsibilities, about the pertinent concepts to the discipline (Physics), some teaching trends and their applications, the current school structure. (Pre-service teachers' initial questionnaire: Daniel, April 2010)

From the beginning, pre-service teachers expect this confrontation. Pre-service teachers cope with a wide range of difficulties from which their identities are formed. This experiences in and through practicum are relevant for identity formation, reinforcing or challenging their initial disposition. In this case, teacher identity seems to be part of the meaning making process of the teaching activity, which, in turn, shapes their agency in School setting. Their concrete agency in School impacts and is impacted by this contradictory encounter between future teachers' expectations and their actual experiences.

\section{Discussion}

Zeichner (2009, p. 9) indicated that "even in the current wave of School-University partnerships in teacher education, colleges and universities continue to maintain hegemony over the construction and dissemination of knowledge". Moreover, Schools remain in the position of practice fields "where student teachers are to try out the practices provided by the University". This type of one hand relationship in which University sets goals and strategies upon School is reflected in the concrete social dynamic during the practicum. As the literature corroborates, the unbalanced partnership between University and School reflects negatively in the development of mentoring as well as in the pre-service teacher learning opportunities (Zeichner, 2009; Keogh, 2010).

Regarding the contradictory processes within the School, Chetcuti \& Buhagiar (2014) underline that the current model for initial teacher education might be reformulated in terms of the community of practice. The authors indicated "This can lead to the apprenticeship model where the expert shows the apprentice how to do a task, the apprentice observes before starting to practice the skills involved, and then gradually takes more responsibility of his or her own 
learning." (Chetcuti \& Buhagiar, 2014, p.48) To a large extent, it is aligned with the findings presented.

On the one hand, the practicum might operate as a positive influence toward teacher identity. It might build a meaningful experience for newcomer teachers. On the other hand, the practicum confronts the pre-service teachers with their career, difficulties, and challenges. Hence, it might exacerbate the career dropout, what is align with the national tendency (Santos \& Curi, 2012, Vargas, 2012). Additionally, one should take into account the undervalue of teacher career in Brazilian context (Vargas, 2012), which might severely impact the pre-service teacher's decision to carry on after the practicum.

The current literature supports the idea that School should be an active part of pre-service teacher's instructions (Edwards \& Protheroe, 2004; Ferrier-Kerr, 2009; Zeichner, 2009). Nevertheless, the models and institutional scheme developed so far lag behind in describing the particular and general mechanisms of institutional partnership.

Commonly, the University and School connections are seen as natural and unproblematic, however, the results presented indicate that pre-service teachers are still strongly connected to University tasks when in the School setting. The results also indicate that the connections between University and School evolve through contradictions which range from the institutional level to the personal as well as professional levels. This aspect is corroborated by the literature (Ferrier-Kerr, 2009). Ultimately, the results show some detailed mechanisms that underpin the institutional partnership.

\section{Conclusions}

The pre-service teachers' agency is shaped by contradictions of the activity - practicum, rather than aligned forces pushing towards autonomy, student sensitiveness or professional identity. The modeling of teacher development in initial teacher training is much more complex and evolves in several levels. Such a complex, multilevel and contradictory process runs from how the practicum is institutionalized as cooperative stance between University and School, incorporated within Schools and classrooms, and embodied as identity formation.

In this research, it is depicted what seems to be the core process in each level. Contradiction as an analytical tool allows the researchers to see beyond the apparent obstacles or shortages, it reveals a deeper dynamic, which should be taken into account when analyzing the practicum. So far, the results provide a picture of contradictions, but it is important to bear in mind that all contradictions presented and discussed evolve in time and are strongly dependent of practitioners' agency. The way students conceptualize the contradiction between University and School changes throughout the academic year and demands further investigation.

Practically, this analytical framework makes possible to outline the subjects' development even when the particular context indicates the contrary. As examples indicated, the situation in which there is little control eventually demands extra efforts but leaves room for active participation. The data analysis indicates that the source of agency and activities transformation is precisely in the contradictory process, which might be overlooked because the theoretical framework is not able to disentangle the processes in teacher development. Finally, the practicum has a great number of elements and participants that, in many cases, rub against each other, producing something meaningful for practitioners and researchers.

It should be underlined that practicum is a crossing boundary activity in many ways. Pre-service Science teachers have to move across institutions as well as they have to move their own position in the whole activity - from student to teacher. From the results, it is possible to conclude that the pre-service teacher's agency is shaped, above all, in contradictory processes, rather than a linear force that leads them to autonomous practice. 
André Machado RODRIGUES, Cristiano Rodrigues de MATTOS. The contradictory nature of teacher education in the partnership between university and school

\section{PROBLEMS \\ OF EDUCATION \\ IN THE $21^{\text {st }}$ CENTURY Vol. 76, No. 1,2018 \\ 98 References}

Akkerman, S., \& Bruining, T. (2016). Multilevel boundary crossing in a professional development school partnership. Journal of the Learning Sciences, 25 (2), 240-284. https://doi.org/10.1080/10508406 .2016.1147448. who teach physics in high school]. Ciência \& Educação, 18 (4), 837-849. https:// doi.org/10.1590/S1516-73132012000400007.

Anagnostopoulos, D., Smith, E. R., \& Basmadjian, K. G. (2007). Bridging the university-school divide horizontal expertise and the "two-worlds pitfall". Journal of Teacher Education, 58 (2), 138-152. https://doi.org/10.1177/0022487106297841.

Barretto, E. S. D. S. (2015). Teacher education policies in Brazil: Contemporary challenges. Revista Brasileira de Educação, 20 (62), 679-701. https://doi.org/10.1590/S1413-24782015206207.

Chetcuti, D., \& Buhagiar, M. (2014). Assessing the field placement in initial teacher education: Finding a balance between formative and summative assessment. Problems of Education in the 21st Century, 58, 39-52.

Edwards, A., \& Protheroe, L. (2004). Teaching by proxy: understanding how mentors are positioned in partnerships. Oxford Review of Education, 30 (2), 183-197. https://doi.org/10.1080/0305498042 000215511.

Engeström, Y. (1987). Learning by expanding: An activity-theoretical approach to developmental research. Helsinki: Orienta-Konsultit.

Engeström, Y. (2001). Expansive learning at work: Toward an activity theoretical reconceptualization. Journal of Education and Work, 14 (1), 133-156. https://doi.org/10.1080/13639080020028747.

Engeström, Y., Engeström, R., \& Kärkkäinen, M. (1995). Polycontextuality and boundary crossing in expert cognition: Learning and problem solving in complex work activities. Learning and Instruction, 5 (1), 319-336.

Engeström, Y., \& Sannino, A. (2011). Discursive manifestations of contradictions in organizational change efforts: A methodological framework. Journal of Organizational Change Management, 24 (3), 368-387. https://doi.org/10.1108/09534811111132758.

Fazio, X., Melville, W., \& Bartley, A. (2010). The problematic nature of the practicum: A key determinant of pre-service teachers' emerging inquiry-based science practices. Journal of Science Teacher Education, 21 (6), 665-681. https://doi.org/10.1007/s10972-010-9209-9.

Fereday, J., \& Muir-Cochrane, E. (2008). Demonstrating rigor using thematic analysis: A hybrid approach of inductive and deductive coding and theme development. International Journal of Qualitative Methods, 5 (1), 80-92. https://doi.org/10.1177/160940690600500107.

Ferrier-Kerr, J. L. (2009). Establishing professional relationships in practicum settings. Teaching and Teacher Education, 25 (6), 790-797. https://doi.org/10.1016/j.tate.2009.01.001.

Gatti, B. A. (2014). Formação inicial de professores para a educação básica: pesquisas e políticas educacionais [Initial teacher training for basic education: research and educational policies]. Estudos em Avaliação Educacional, 25 (57), 24-54. http://dx.doi.org/10.18222/eae255720142823.

Hahn, S. S. (2007). Contradiction in motion: Hegel's organic concept of life and value. Cornell: Cornell University Press.

Harfitt, G. J., \& Tavares, N. J. (2004). Obstacles as opportunities in the promotion of teachers' learning. International Journal of Educational Research, 41 (4-5), 353-366. https://doi.org/10.1016/j. ijer.2005.08.006.

Hong, J. Y. (2010). Pre-service and beginning teachers' professional identity and its relation to dropping out of the profession. Teaching and Teacher Education, 26 (8), 1530-1543. https://doi.org/10.1016/j. tate.2010.06.003.

Ilyenkov, E. V. (1977). Dialectical logic: Essays on its history and theory. Moscow: Progress Publishers. Institute of Physics. (2008). Syllabus booklet for teacher education program. São Paulo: Institute of Physics - University of São Paulo.

Janssen, F., Westbroek, H., \& Doyle, W. (2014). The practical turn in teacher education: Designing a preparation sequence for core practice frames. Journal of Teacher Education, 65 (3), 195-206. https://doi.org/10.1177/0022487113518584.

Jooganah, K., \& Williams, J. S. (2016). Contradictions between and within school and university activity systems helping to explain students' difficulty with advanced mathematics. Teaching Mathematics and Its Applications: An International Journal of the IMA, 35 (3), 159-171. https:// doi.org/10.1093/teamat/hrw014. 
André Machado RODRIGUES, Cristiano Rodrigues de MATTOS. The contradictory nature of teacher education in the partnership between university and school

Kadri, M. S. E., \& Roth, W.-M. (2015). The teaching practicum as a locus of multi-leveled, school-based transformation. Teaching Education, 26 (1), 17-37. https://doi.org/10.1080/10476210.2014.997 700.

Kapustka, K. M., Howell, P., Clayton, C. D., \& Thomas, S. (2009). Social justice in teacher education: A qualitative content analysis of NCATE conceptual frameworks. Equity \& Excellence in Education, 42 (4), 489-505. https://doi.org/10.1080/10665680903260101.

Keogh, J. (2010). (In) forming formal evaluation: Analysis of a practicum mentoring conversation. Journal of Applied Linguistics and Professional Practice, 7 (1), 51-73. https://doi.org/10.1558/ japl.v7i1.51.

Lampert, M. (2010). Learning Teaching in, from, and for Practice: What Do We Mean? Journal of Teacher Education, 61 (1-2), 21-34. https://doi.org/10.1177/0022487109347321.

Ministry of Education of Brazil. Resolution number 2 of 1st July 2015. (2015).

Roth, W.-M. (2005). Doing qualitative research: Praxis of method. (Vol. 3). Rotterdam: Sense Publishers.

Santos, C. A. B. dos, \& Curi, E. (2012). A formação dos professores que ensinam física no ensino médio [The training of teachers who teach physics in high school]. Ciência \& Educação, 18 (4), 837 849. https://doi.org/10.1590/S1516-73132012000400007.

Shulman, L. S. (1987). Knowledge and teaching: foundations of the new reform. Harvard Educational Review, 57 (1), 1-22. https://doi.org/10.17763/haer.57.1.j463w79r56455411.

Sobrinho, J. D. (2006). Changes in Brazilian higher education and their effects on the enhancement of teaching (1995-2005). New Directions for Higher Education, 2006 (133), 91-99. https://doi. org/10.1002/he.209.

Tsui, A. B. M., \& Law, D. Y. K. (2007). Learning as boundary-crossing in school-university partnership. Teaching and Teacher Education, 23 (8), 1289-1301. https://doi.org/10.1016/j.tate.2006.06.003.

Vargas, H. M. (2012). Teacher careers and teacher education: A Brazilian dilemma. Problems of Education in the 21st Century, 47, 144-151.

Villani, A., Pacca, J. L. de A., \& Freitas, D. de. (2009). Science teacher education in Brazil: 1950-2000. Science \& Education, 18 (1), 125-148. https://doi.org/10.1007/s11191-007-9116-4.

Vygotsky, L. S. (1978). Mind in society: The development of higher psychological processes. Harvard University Press.

Whitney, L., Golez, F., Nagel, G., Nieto, C., \& Nieto, C. (2002). Listening to voices of practicing teachers to examine the effectiveness of a teacher education program. Action in Teacher Education, 23 (4), 69-76. https://doi.org/10.1080/01626620.2002.10463090.

Yamagata-Lynch, L. C., \& Haudenschild, M. T. (2009). Using activity systems analysis to identify inner contradictions in teacher professional development. Teaching and Teacher Education, 25 (3), 507-517. https://doi.org/10.1016/j.tate.2008.09.014.

Zeichner, K. (2009). Rethinking the connections between campus courses and field experiences in college- and university-based teacher education. Journal of Teacher Education, 61 (1-2), 89-99. https://doi.org/10.1177/0022487109347671.

Received: December 12, 2017

Accepted: February 26, 2018

André Machado Rodrigues

Cristiano Rodrigues de Mattos
$\mathrm{PhD}$, Assistant Professor, Institute of Physics, University of São Paulo, Rua do Matão, Travessa R, 187, São Paulo, Brazil.

E-mail: rodrigues@if.usp.br

PhD, Professor, Institute of Physics, University of São Paulo, Rua do

Matão, Travessa R, 187, São Paulo, Brazil.

E-mail: mattos@if.usp.br 